\title{
In Memoriam: Fernando Lopes da Silva (1935-2019)
}

\author{
Christoph M. Michel ${ }^{1}(1)$. Sylvain Baillet ${ }^{2} \cdot$ Christian Benar $^{3} \cdot$ Olivier Bertrand $^{4} \cdot$ Jean Gotman $^{5} \cdot$ Bin $\mathrm{He}^{6}$. \\ Geert-Jan Huiskamp $^{7} \cdot$ Louis Lemieux $^{8} \cdot$ Scott Makeig $^{9} \cdot$ Alvaro Pascual-Leone $^{10} \cdot$ Riitta Salmelin $^{11} \cdot$ Stefano Seri $^{12}$. \\ Pedro Valdes-Sosa ${ }^{13} \cdot$ Fabrice Wendling $^{14}$
}

Received: 22 May 2019 / Accepted: 2 June 2019 / Published online: 8 June 2019

(c) Springer Science+Business Media, LLC, part of Springer Nature 2019

Fernando Lopes da Silva was one of the most influential neurophysiologists of our time (Fig. 1). For half a century he enriched the neuroscience community with his research on the mechanisms generating electrophysiological brain activity. His fundamental discoveries provided the basis for the interpretation of countless empirical research results.

Fernando Lopes da Silva was born in Lisbon on January 24,1935 . In 1959, he graduated in medicine from the University of Lisbon and undertook post-graduate training in the UK (Mill Hill and Imperial College London) in 1962-64; he then moved to the Netherlands in 1965 and received his $\mathrm{PhD}$ degree in 1970 from the University of Utrecht. In 1973, he followed W. Storm van Leeuwen as Head of the Brain

Handling Editor: Christoph M. Michel.

On behalf of the Editors-in-Chief, the Associate Editors and the members of the Editorial Board of Brain Topography, the authors express their deepest grief over the death of their esteemed colleague, mentor and friend, Fernando Lopes da Silva, who passed away on May 7, 2019 at the age of 84 .

Christoph M. Michel

christoph.michel@unige.ch

Sylvain Baillet

sylvain.baillet@mcgill.ca

Christian Benar

christian.benar@univ-amu.fr

Olivier Bertrand

olivier.bertrand@inserm.fr

Jean Gotman

jean.gotman@mcgill.ca

Bin $\mathrm{He}$

bhe1@andrew.cmu.edu

Geert-Jan Huiskamp

g.j.m.huiskamp@umcutrecht.nl

Louis Lemieux

louis.lemieux@ucl.ac.uk
Research Group of the Institute of Medical Physics (TNO) in Utrecht. In 1980 he was appointed Full Professor of General Physiology at the Faculty of Science at the University of Amsterdam where he was from 1993 to 2000 director of the newly created Institute of Neurobiology of the University of Amsterdam, and member of the Scientific Directorate of the Graduate School Neurosciences Amsterdam. From 1995 to 2002, he also was the Scientific Director of the Foundation of Epilepsy Clinics of the Netherlands at "Meer en Bosch" in Heemstede.

His official retirement in 2000 did not stop his research career. In contrary, more than 100 of his numerous research papers appeared after his official retirement age. While still
Scott Makeig

smakeig@ucsd.edu

Alvaro Pascual-Leone

apleone@me.com

Riitta Salmelin

riitta.salmelin@aalto.fi

Stefano Seri

s.seri@aston.ac.uk

Pedro Valdes-Sosa

pedro.valdes@neuroinformatics-collaboratory.org

Fabrice Wendling

fabrice.wendling@inserm.fr

Department of Basic Neurosciences, University of Geneva, Geneva, Switzerland

2 Montreal Neurological Institute, McGill University, Montreal, QC, Canada 


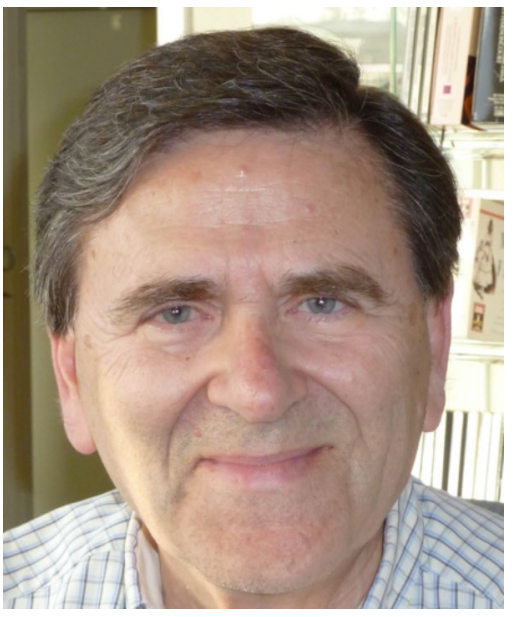

Fig. 1 Fernando Lopes da Silva, 1935-2019

being Emeritus Professor in Amsterdam, and despite his beloved seats at the Royal Concertgebouw hall for classical music, he often returned to his home country, Portugal. In 2000, he became visiting Professor of the Faculty of Medicine of the University of Lisbon, and in 2005 was appointed Professor at the 'Instituto Superior Técnico' of the Technical University of Lisbon with the task of coordinating teaching and research in 'Bio-Medical Engineering'. He was actively involved in the supervision of MSc and PhD students in this Institute.

His robust, constructive criticism of all work he was shown was notorious. In the late 2000's and early 2010's Fernando chaired the Health Sciences committee of the Portuguese Foundation for Science and Technology (FCT). Not only contributing to science, Fernando also helped coordinating international peer review of grant proposals related to biomedical engineering in Portugal, and was instrumental in promoting biomedical engineering there. As member of

3 Aix Marseille Université, Institut de Neurosciences des Systèmes, Marseille, France

4 Lyon Neuroscience Research Center (CRNL), INSERM, CNRS, Université de Lyon, Lyon, France

5 Montreal Neurological Institute and Hospital, McGill University, Montreal, QC, Canada

6 Department of Biomedical Engineering, Carnegie Mellon University, Pittsburgh, USA

7 Department of Neurology and Neurosurgery, Brain Center Rudolf Magnus, UMC Utrecht, Utrecht, The Netherlands

8 Department of Clinical and Experimental Epilepsy, UCL Queen Square Institute of Neurology, London, UK

9 Swartz Center for Computational Neuroscience, Institute for Neural Computation, University of California San Diego, La Jolla, San Diego, CA, USA the General Council of the University of Lisbon he was an enthusiastic supporter of the merger between the "technical" and "classic" Universities in Lisbon. Also outside Portugal, he sat in countless advisory boards and evaluation panels of research centers and peer-review committees of multiple funding bodies worldwide.

Fernando Lopes da Silva received many honors and awards. He was honored with the degree of Doctor Honoris Causa from the University of Lisbon, the University of Porto, the University of Helsinki and very recently from the University of Rennes. He received the Herbert H. Jasper Award of the American Clinical Neurophysiology Society, he was awarded the title of "Alto Oficial da Ordem de Santiago da Espada" by the President of Portugal for his notable contributions to the fields of Science, Arts and Literature, and he was awarded the degree of knight of the order of the "Nederlandse Leeuw" by the Queen of Netherlands. He has been elected member of the Royal Netherlands Academy of Arts and Sciences and was honorary member of the British Society of Clinical Neurophysiology. He gave keynote addresses at innumerable international conferences, such as at the OHBM conference in Geneva in 2016. But Fernando would also accept an invitation by a $\mathrm{PhD}$ student to present at a local bi-weekly colloquium. On 2nd February 2017 he delivered the UCL Centre for Neuroimaging Technique's Annual EEG lecture to a packed room, on his first ever visit to Queen Square. In this lecture he addressed six EEG FAQ's such as "Can the generators of EEG/MEG signals be accounted for, simply by assuming that all cellular sources are dipolar?". It was 'majistral'.

Much of Fernando Lopes da Silva's work was dedicated to the elucidating mechanisms generating rhythmic activities in the brain, particularly the alpha oscillations in the $8-12 \mathrm{~Hz}$ range that are so prominent in the brain. These signals were first reported by early electrophysiologists at the turn of the 20th century, but their functions have remained

10

Department of Neurology, Harvard Medical School, Berenson-Allen, Center for Non-Invasive Brain Stimulation, Beth Israel Deaconess Medical Center, Boston, MA, USA

11 Department of Neuroscience and Biomedical Engineering, Aalto University, Helsinki, Finland

12 School of Life and Health Sciences, Aston Brain Centre, Aston University, Birmingham, UK

13 Universtity of Electronic Sciecne and Technology of China/Cuban Neuroscience Center, La Habana, Cuba

14 University of Rennes, INSERM, LTSI-U1099 Rennes, France 
Fig. 2 Fernando H. Lopes da Silva and Donald L. Schomer, The Editors of "Niedermeyer's Electroencephlography", together with C.M. Michel at the ICCN Conference in Berlin in 2014

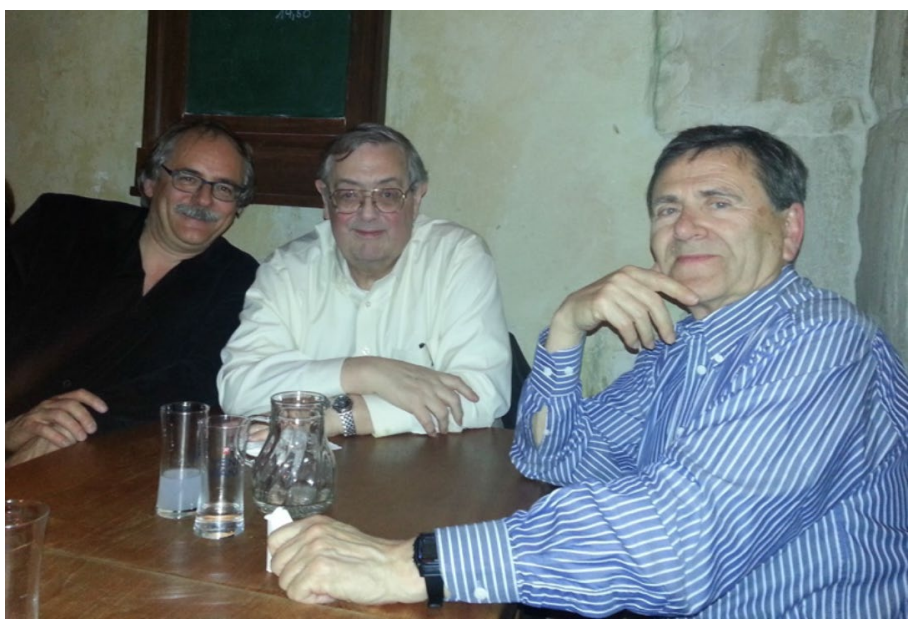

somewhat paradoxically little understood since then. In his groundbreaking paper published in 1977 (Lopes da Silva et al. 1977) Fernando Lopes da Silva demonstrated with intracranial recordings in dogs that the alpha rhythm has not only thalamic but also cortical generators in layers IV and $\mathrm{V}$ of the visual cortex. In another important paper he unraveled the relative contribution of intracortical and thalamo-cortical interactions in the generation of these rhythmic fluctuations (Lopes da Silva et al. 1980). Together with other eminent researchers in the field (Mircea Steriade, Pierre Gloor, Rodolfo Llinas and Marsel Mesulam) he published a seminal review paper entitled "Basic Mechanisms of Cerebral Rhythmic Activities" that has become one of the most cited references in the field (Steriade et al. 1990). His interest in the mechanisms and functional significance of alpha rhythms also led to an intense collaboration with Gert Pfurtscheller on event-related alpha synchronization and desynchronization, resulting in another highly cited review paper published in 1999 (Pfurtscheller et al. 1999). The work on event-related synchronization and desynchronization has had a profound impact on the development of noninvasive brain-computer interface.

Fernando Lopes da Silva was a pioneer in translational research, bridging the gap between basic neuroscience research and clinical applications. His clinical interest focused on epilepsy "as a dynamical disease", as he used to say (Lopes da Silva et al. 2003). The research approach he pioneered and promoted for four decades was based on an insightful combination of computational models and experimental/clinical data. His work on experimental models of generalized spike and wave discharges has changed the way we understand generalized epilepsy, emphasizing the role of cortical trigger regions (Meeren et al. 2002). Over 100 of his research articles co-authored with many international collaborators are dedicated to the mechanisms of epileptogenesis and on methods to predict, detect, and localize seizure generation.
Fernando Lopes da Silva was always interested in noninvasive methods to study the temporal dynamics of neuronal activity, and even published original work performed using fMRI - a technique he appreciated with a healthy dose of skepticism; for him the technique's relative slugishness was a fundamental hurdle, a subject of numerous discussions with some of us. He pioneered many EEG and MEG analysis methods and was instrumental in giving advice to users of these methods. His primer on "EEG and MEG: Relevance to Neuroscience" published in Neuron in 2013 (Lopes da Silva 2013) has been an important guideline for many of us.

Fernando Lopes da Silva also made numerous contributions to basic neurophysiology and neuroanatomy which will not be discussed here. But another extraordinary contribution of Fernando to the community was his dedication to the "EEG Bible", the book Electroencephalography; Basic Principles, Clinical Applications and Related Fields, the standard reference on EEG for a whole generation of clinicians and clinical neurophysiologists. He edited this book for many years together with Ernst Niedermeyer. After Niedermeyer's death, he renamed the book 'Niedermeyer's Electroencephalography" and continued editing it with Donald Schomer. The seventh Edition, published last year has 1217 pages and covers 48 review articles by authors from all over the world (Schomer and Lopes da Silva 2018). All those among us who had the honor to be invited to contribute to this book know that Fernando Lopes da Silva read each and every one of these 1217 pages, commented on them, making cross references between them, and pushing us to make the chapters comprehensive and complete. This incredibly tedious work made it clear to all of us how knowledgeable, competent and thorough Fernando was. Strikingly, this highlydemanding work was always performed in the friendliest atmosphere. Indeed, Fernando was constantly keen to made scientific research most enjoyable. One of his sentences perfectly summarizes the spirit he always promoted "Through science we may reach real friendship". This approach was 
extended across the globe, with a practical and real concern for the development of neuroscience without boundaries. He dedicated much time, often anonymously to ensure that papers and events in other countries would be successful (Fig. 2).

Fernando Lopes da Silva was working until his very last days; characteristically, he was one of the very first to submit an updated version of his chapter on the nature of the EEG, for the 2nd Edition of the book on EEG-fMRI by Mulert and Lemieux (2019). Just 2 weeks before he passed away, he submitted an invited commentary article to Brain Topography. In his letter to the Editor he wrote, "I' $m$ sorry to have to tell you than I am seriously ill and probably this is my last task." The Editors of Brain Topography are profoundly grateful and honored that Fernando Lopes da Silva published one of his last articles in our journal (Lopes da Silva 2019).

Beyond all his many seminal contributions to neuroscience and neurophysiology, for all of us and for entire generations of scientists and clinicians, Fernando Lopes da Silva was above all an inspiration. He was a leader, a mentor, an example to emulate as a scholar, a scientist and a person. His profound intellectual honesty and his kindness marked all those who had to chance to meet him. All fields of knowledge are ultimately shaped by individuals, the people who dare chart a direction and pursue their ideas with commitment, effort, enthusiasm and humble eagerness to learn and share their knowledge. Fernando Lopes da Silva embodied all those attributes and thus has enriched each and everyone of us. We all stand on the shoulders of giants, and hopefully we shall not forget Fernando for allowing us to stand of his.

It is sad to realize that he and his knowledge and wisdom will no longer be here for us to count on in future, but his legacy will continue to inspire all of us. We will miss Fernando Lopes da Silva deeply.

\section{References}

Da Silva FL (2013) EEG and MEG: relevance to neuroscience. Neuron 80(5):1112-1128

Da Silva FL (2019) Intracerebral sources reconstructed on the basis of high-resolution scalp EEG and MEG. A commentary on publications by Pizzo et al. and Seeber et al. Brain Topogr. https://doi. org/10.1007/s10548-019-00717-9

Da Silva FL, Van Leeuwen WS (1977) The cortical source of the alpha rhythm. Neurosci Lett 6(2-3):237-241

Da Silva FL, Vos JE, Mooibroek J, Van Rotterdam A (1980) Relative contributions of intracortical and thalamo-cortical processes in the generation of alpha rhythms, revealed by partial coherence analysis. Electroencephalogr Clin Neurophysiol 50(5-6):449-456

Da Silva FL, Blanes W, Kalitzin SN, Parra J, Suffczynski P, Velis DN (2003) Epilepsies as dynamical diseases of brain systems: basic models of the transition between normal and epileptic activity. Epilepsia 44:72-83

Meeren HK, Pijn JPM, Van Luijtelaar EL, Coenen AM, Da Silva FL (2002) Cortical focus drives widespread corticothalamic networks during spontaneous absence seizures in rats. J Neurosci 22(4):1480-1495

Mulert C, Lemieux L (eds) (2019) EEG - fMRI: physiological basis, technique, and applications, 2nd edn. Springer Nature, Berlin, Heidelberg, in preparation

Pfurtscheller G, da Silva FL (1999) Event-related EEG/MEG synchronization and desynchronization: basic principles. Clin Neurophysiol 110(11): 1842-1857

Schomer DL, Da Silva FL (eds) (2018) Niedermeyer's electroencephalography; basic principles, clinical applications, and related fields. Oxford University Press, New York

Steriade M, Gloor P, Llinás RR, Da Silva FL, Mesulam MM (1990) Report of IFCN Committee on basic mechanisms. Basic mechanisms of cerebral rhythmic activities. Electroencephalogr Clin Neurophysiol 76(6):481-508

Publisher's Note Springer Nature remains neutral with regard to jurisdictional claims in published maps and institutional affiliations. 